\title{
CORRECTIONS
}

\section{Dr McCartney is right, the BMA is wrong}

This letter by Colm P O'Mahony and colleagues states that in Northern Ireland cervical screening is offered from the age of 20 (BMJ 2011;343:d6679, doi:10.1136/bmj.d6679). However, we have been advised by the Northern Ireland Cervical Screening Programme and Belfast's Department of Health that the policy changed in January 2011 and that the Northern Ireland
Cervical Screening Programme no longer invites women aged under 25 . They say that this policy position is based on the best available evidence and is in line with the approach in England.

Cite this as: BMJ 2011;343:d7808

๑ BMJ Publishing Group Ltd 2011 